\title{
Qualitative Improvement in Teaching-Learning at Higher Education Level - An Introspection
}

\author{
Dr. Mani Joshi \\ Asstt. Prof. (Sr. Grade), Dept. of B.Ed. \\ Shri Jai Narain Misra P.G. College, Lucknow \\ Email:manijoshi9@yahoo.com
}

\begin{abstract}
The main aim of education is to provide the individual maximum possible opportunities so as to enable him to develop his abilities and areas of interest to the maximum on one hand and to make him capable of living a respectable life involving service to the nation on the other. Rapid globalization has led to an urgent need of deep introspection of higher education system for which quality and quantity both are important. The experience pouring out of privatization of education has indicated the need of a more strict and transparent regulatory body to check the qualitative aspect of education. Also digitalization and online learning needs a lot of improvement so as to enable maximum students to benefit from it. Although we are not sure about the future, we should try to make intelligent decisions and be more strategic and specific for the coming days.

Keywords : Teaching Methods, Teaching Models, Paradigm shift, Online learning, Blended learning, e-gathering approach, Digital learning, Quality and Excellence, Social Values, Equal Access.
\end{abstract}

Reference to this paper should be made as follows:

Received: 21.04.2019

Approved: 25.09.2020

Dr. Mani Joshi

Qualitative Improvement in Teaching-Learning at Higher Education Level An Introspection

Article No. 19

RJPSS Sept. 2020,

Vol. XLV No. 2,

pp. 163-171

Online available at:

https://anubooks.com/rjpss-

2020-vol-xlv-no-2/

https://doi.org/10.31995/

rjpss.2020.v45i01.019 
litative Improvement in Teaching-Learning at Higher Education Level-An Introspection

Dr. Mani Joshi

\section{Introduction}

In the early days of independence, India's educationists felt that it was not possible to find the right path without altering the structure of higher education. In order to educate itself, society has to resort to modernization. It must make an effort to create a class of educated individuals, drawn from every part of society, whose beliefs and ambitions bear the deep imprint of Indianism. In a democracy, the end is the individual himself. The major purpose of higher education is to grant the individual maximum possible opportunities for the fullest development of his capabilities.

In this growing era of globalization the role of higher education becomes increasingly important, particularly in the field of economic growth and icresing competition. Hence, there is an urgent necessity for its qualitative improvement. There have been quantitative and financial spread but its proper use is missing. The educational institutions are producing gradutes with just a dgree which does not guarantee employment or bright future. There is a huge gap between industry demand and outcome of our education system.

Enhancement of academic quality has become one of the most important policy imperatives for higher education institutions all over the world. The quality of human resource development and knowledge production is seen as a major driver for the competitiveness of national economies. Therefore, governments lay major emphasis on this aspect in their higher education policies and planning documents, and institutions respond by making quality enhancement as one of their most important strategic objectives. This pattern is especially observed when higher education becomes a competitive market, where quality becomes a tool to consolidate the market positioning of institutions.

There is much discussion these days about quality in higher education throughout all quarters of the higher education community and outside the community, as well. Government officials, employers, accrediting agencies, university administrators, institutional researchers, faculty, and faculty development specialists all have something to share concerning this topic. At the moment, however, we are experiencing more of a cacophony of speech rather than a conversation about quality.

The quality of higher education in India needs to be reassessed. There is a confusion amongst the educational institutions that quality can be achieved by abundant internal resources, huge infrastructure, big campus and a larege number of facilities only. However, this is not enough. What is required is values, value education, deep understanding and knowledge, ability to solve problems in difficult situations and recalling what is taught at the right time etc. The education needs to be skill-based and directly related to real-life situations and industry demands. 
RJPSS Sept. 2020 Vol. XLV No.2, ISSN: (P)0258-1701 (e)2454-3403 Impact Factor: 7.717

\section{Recommendations}

https://doi.org/10.31995/rjpss.2020.v45i01.019

To keep India abrest in the field of education, the Indian government entrusted Dr. S. Radhakrishnan to give suggestions to improve higher education in India (194849). Radhakrishnan Commission on University Education suggested that "The most important and urgent reform needed in education is to transform it, to endeavor to relate it to the life, needs, and aspirations of the people and thereby make it the powerful instrument of social, economic and cultural transformation necessary for the realization of the national goals. For this purpose, education should be developed so as to increase productivity, achieve social and national integration, accelerate the process of modernization and cultivate social, moral, and spiritual values."

It was only in 1964 that central education minister Justice Chagla entrusted Dr. D.S. Kothari to tackle problems of Indian education at all levels i.e. higher, secondary, and primary plus link education with productivity and rationalization. The twin goals were hard to achieve in the face of a fast-growing population, information, and aspiration explosion and were a hard nut to grab.

Higher education teachers, though scholars of note were not aware of methods and methodology of transforming new information to their students. Unrest and indiscipline were the results. New Education Policy (1986) and Revised New Education policy (1992) had been groping in the dark to make higher education utilitarian. Dr. Kapoor (the then Vice-Chancellor of Meerut University) after returning from Australia pointed out that to improve higher education "it should be objective oriented and must solve national, social, economic and political problems". The aspect of evaluation in higher education was also very confusing. For these, he suggested oriental courses, workshops, etc.

In the 'National Knowledge Commission' (2005) Sam Pitroda recommended that to improve teaching at a higher level 'quality' and 'global standards' should be maintained in teaching methods, evaluation, and research work. He also suggested that syllabus and content should be critically evaluated for higher education every three years. 'Memory', 'comprehension' and 'creativity' should be given importance in evaluation. Further, he opined that the Indian Association of Science Teachers should be supported to develop new teaching methods, content, and evaluation techniques.

\section{Scientific and Technological Angles}

In higher education from a scientific and technological viewpoint, a teacher must teach students how to think' and 'how to put theory into practice'. Teaching 
$\checkmark$ Heuristic Method (to discover or to investigate) : It helps to develop scientific attitude and divergent $\&$ imaginative thinking.

$\checkmark \quad$ Problem Solving Method (scientific method) : It develops planning, thinking, and reasoning skills in the students.

$\checkmark \quad$ Inductive - deductive Method : It is a good method of teaching science and social sciences. With the help of the inductive method generalization or conclusions are drawn on the basis of experiments and observations while by deductive method facts are deducted or analyzed by the application of the established formula.

$\checkmark \quad$ With the help of different teaching strategies like Autocratic (lecture, demonstration, and tutorial) and Democratic (heurism, project, discovery, and programmed instruction).

$\checkmark$ By following basic elements of 'Teaching Models' as Focus (refers to instructional objectives of teaching), Syntax (description of activities during teaching), Social System (use of teaching skills while teaching), Support System (hardware \& software technologies and electronic gadgets), Evaluation (objective test and recapitulation) to measure the learning outcome and to make teaching and learning effectively at a higher level, as suggested by Morrison, Glaser, and B.S. Bloom.

Modes of transfer of learning are no doubt today having grown up like mushrooms attract our attention. As teaching-learning situations are very many, so are the approaches and trends. Types and kinds may be bunched yet every new situation demand a new strategy in every discipline and for every topic thereof. A teacher who enters the teaching profession starts searching his bag to find out some teaching style which would be new and attractive to the educands yet there lurks the hesitation, will it be a welcome style.

Woodworth, the great German behaviorist, and even Bloom seem to have joined hands that successful teaching would be that which brings the desired change in the behaviour of learners. Skinner helps us when he opines 'smaller the unit greater the achievement'. In cognitive domain if the learner learns to define terms, facts, and concept, it can be inferred that he has gained knowledge; if he justifies or condemns the results, means he has understood new information; if the learner applies newly learned laws in new situations, if he is able to analyze, identify and infer facts, it makes us sure that he has learned to analyze; if he is able to state the theme and to justify or conclude, it is inferred that he is able to evaluate. In the psychomotor domain he is able to assemble and build figures, perform cultural activities, construct, 
RJPSS Sept. 2020 Vol. XLV No.2, ISSN: (P)0258-1701 (e)2454-3403 Impact Factor: 7.717 https://doi.org/10.31995/rjpss.2020.v45i01.019 correct, or weigh; but if he further enquires, discusses, quotes, recipes, and studies further, he has entered the affective domain by gained information.

\section{Trends in Higher Education}

It is an accepted working policy of all the democratic nations to make provision for equal educational opportunities for all. In the Higher Education Commission, it has been pointed out that "Democracy only provides that all men should have equal opportunities for the development of their unequal talents". The Commission has also pointed out that "One of the important social objectives of education is to equalize opportunity enabling the backward or underprivileged classes and individuals to use education as a lever for the improvement of their condition". Even the Preamble of the Constitution also ensures equality for all the citizens. It means that our Constitution is committed to the principle of equality. Every society that values social justice must ensure progressive equality of opportunity to all sections of the population. This is the only guarantee of an egalitarian and human society by which exploitation of the weak will be minimized.

The equalization of educational opportunities is essentially linked with the equality notions in the social system. The need for emphasizing the equality of opportunity in the education is the need of the hour for various reasons. It is needed for the establishment of an egalitarian society based on social equality and justice. It contributes to the search for talents and thus ensuring the rapid advancement of the nation. It is an important base for the successful functioning of the democracy. The Government of India has also been striving to achieve the target of providing equal educational opportunities to all the people along with inclusive education.

In higher education, everything that needs to be done is very much known. We are all very clear about the challenges in front of us but we still keep debating and discussing, and not acting. The institutions that were created years ago have become obsolete. We know it all but we are not willing to accept the same. We need course wise credit; we need to use technology effectively. We are known all over the world for expertise in IT but we use very little of information and communication technology in our education especially in higher education. Teacher today spends most of his or her time in delivering and creating content. Content is already there. Role of a teacher will have to change to that of a mentor. Most of our teachers don't do research and most of our research scientists don't teach. We have to bring them together.

It appears that the education system in India is lacking what is required most. For many years we did not give due importance to research leading to decline in its quality and even quantity. Privatization has resulted in quantitative progress but the qualitative aspect is missing to a great extent. There appears to be lack of proper 
planning and a powerful regulatory body which has enough powers along with transparency.

In an era where new information is dropping down in the form of storms, it is a challenge in front of the teacher as to how to analyze, systematize, classify, and categorize the new information. How and how much is to be provided, is also a challenge. We must teach our students 'How to Think' and 'How to put Theory into Practice'. Teaching methods and methodology need to be improved a lot at the higher education level. Still, in most of the colleges, the only way of teaching and learning is verbal or through the lecture method. Teachers have inadequate knowledge of hardware and software technologies. To make classroom teaching effective, 'Content Analysis', Pedagogical Analysis', and 'Teaching-Learning Objective' must be very clear to the teacher. 'Content and Communication' must be properly analyzed through the use of 'Information Communication Technology' (ICT) because teachers are the key transformers. Thus, only effective and quality-oriented classroom teaching at a higher level can enhance the process of learning and will surely develop the skills of Head, Heart, and Hand.

In this era of fast changing world the policies, laws and education system of any country has to face stiff competition from hardships born out of globalization. Teaching-learning and skill-development have to be according to pace and demand of fast changing industry and market demand. Outsourcing is there and going to increase in coming days. The world is heading towards one-globe one-market. Specialist skilled youth have to be interchanged within different countries according to their requirements. There is a bright future for skilled youth but that skill should be latest, practical and real and not only on the papers in the form of degrees and diplomas. Quality is the key to everything. But moral values of a country should also be kept in mind accordingly.

For a teacher to be able to impart moral and value education, first he should himself be equipped with these values and should have depth and intellect in his personality. He should not only try to infuse skilled knowledge, moral and values in the student but at the same time should also try to remove the ills of ego and domination. Teacher is the most important pillar of the education system. It is teacher who can build a nation.

Like any other system, higher education keeps on changing in response to internal and external conditions. Changes in technology have radically altered the manner in which faculty teach, conduct research, and even enter grades. The decline of agrarian and manufacturing economies and the growth of the knowledge economy have significantly advanced the emphasis on higher education's role in preparing people for the professions and has set the stage for rudimentary comparative analysis 
RJPSS Sept. 2020 Vol. XLV No.2, ISSN: (P)0258-1701 (e)2454-3403 Impact Factor: 7.717

https://doi.org/10.31995/rjpss.2020.v45i01.019

of institutional performance. The growing conversation and increasing awareness of how we define quality, and how we adopt quality principles and methods, will likewise affect the higher education culture as more leaders and stakeholders recognize and embrace these principles. In the words of Brent Ruben, from Rutgers University: "How we think about excellence has fundamental implications for illuminating and reconciling differences in perspective and priority within the academy."

\section{Higher Education during COVID-19 Pandemic}

In the present scenario when we are facing the COVID-19 pandemic then the face of education has dramatically changed, with the distinctive need for elearning and continuance of teaching-learning over remote and digital platforms. The incorporation of information communication technology in education has already been on a high growth even before the pandemic. However, the sudden closure of educational institutions in many parts of the world has brought a certain emergency to adopt online teaching-learning strategies which are likely to continue even post COVID-19. Hence the teaching community needs to evolve, more than ever, an innovative approach to equip themselves with the skills for creating a holistic learning environment in an unprecedented context. It is a challenge for a teacher how to teach and have an interaction with learners which is now accepted by the teachers positively at all the three levels of education due to digitalization. The role of the teacher has changed from real classroom to virtual teaching-learning conditions.

It is very important that there should be a paradigm shift in the education because the need of the hour is to change the process of teaching-learning to secure the future of the learners by using the internet, online and blended teaching-learning mode by using e-content in the form of audios, videos, PDFs, e-books, e-libraries, etc. teachers have to understand themselves and others that is to develop the ability of self-analysis and self-evaluation to become a professionalist. Shift in the practice to a professional approach, shift from information-based to experience-based approach, change in the traditional approach to newer constructivism is a challenge and operationalization of curriculum by both i.e. teacher and taught. Need of the hour is to convert content according to Indian conditions and situations to connect with students so that they may become self-motivated and self-guided. To develop concept clarity, competency, communication skills in the student's teacher has to be a warrior. Thus redefining online education as a tool for interaction is a must for a teacher along with the change in the mindset of parents is required.

COVID-19 is a global problem so collaboration in education and a universally accepted model of education is the need of the hour. Unlocking technologies, indigenous use of technology, to make learners learn the 'art of living quality life' along with due importance to 'health and hygiene' and the knowledge of good parenting 
skills for unexpected situations and resiliency, etc. to change the mindset of the learners. For the $21^{\text {st }}$ century, learners' teachers should be compassionate and considerate so that there may be a perfect harmony between teachers, students, researchers, parents, and the entire teaching community. Teacher should agree to practice patience in this time i.e. unlocking happiness in the pandemic environment.

Today the education system is in the transitional phase as a learner is bombarded with information. For this learning mode needs to be changed, the medium of instruction needs change as there is stress on all levels i.e. teachers, learners, parents, and learning community. 'Flipkart pedagogical approach' is the need of the hour i.e. indigenous learning stage resulting in an interactive learning stage so as to engage maximum learners in the learning process and to train the learners to become researchers to analyze and synthesize the outburst flow of content according to their needs.

'Teacher is a compass' and 'students are navigators' so the teacher himself has to develop a culture of online teaching to maximize learning outcomes and to create happiness in the classroom. Thus paradigm shift is from conventional teachinglearning to ICT based teaching-learning through online digital programs so that knowledge may reach to doorstep. Need-based curriculum, modular courses, and econtents are must make learning effective and to empower the learners for the future as well as to deal present situation in a positive way and for inculcating employment capacity and user-friendly approach of learning.

Quality education can be interpreted in differend ways - it may be relative and it may be absolute. This absoluteness or perfection is the most important aspect of education. Perfection is required in every field of education - in curriculum development, in evaluation, in progress and so on. For achieving this or a stage near to this different institutions may share their successful experiments and ideas with others for betterment of higher education.

\section{Conclusion}

Higher education must help to achieve the full human potential to develop an equitable and just society for promoting national development. Providing universal access to quality education is key to economic growth, social justice and equality, scientific advancement, national integration, and cultural preservation and high-quality educational opportunities, progress, and leadership on the global stage will surely shape the future of our country. Thus higher education must move towards learning about how to think critically and solve problems, how to adapt, and absorb new material in the novel and changing fields. Higher education must also help to build character, enable learners to be ethical, rational, compassionate, and caring, while at the same time prepare them for fulfilling employment. 
RJPSS Sept. 2020 Vol. XLV No.2, ISSN: (P)0258-1701 (e)2454-3403 Impact Factor: 7.717 https://doi.org/10.31995/rjpss.2020.v45i01.019

The role of digital education will surely bring social change by following the "re-gathering approach" and e-learning will change the mode of delivery and the pattern of assessment in the present scenario. Thus the need-based pattern of education will definitely rejuvenate the society by smart learning, producing smart educators and smart learners which will change the traditional trend of education according to present requirements.

Although we are not sure about the future, we should try to make intelligent decisions and be more strategic and specific for the coming days. Nothing is certain in the future except change as the saying goes, yet being proactive rather than reactive will certainly lead our education system towards a better position for bright future.

\section{References}

1. Agarwal P. (2006) : Higher Education in India: The Need for Change, ICRIER Working Paper, Indian Council for Research on International Economic Relations, 180.

2. Ananda Krishnan M. (2006) : Privatization of Higher Education: Opportunities and Anomalies. New Delhi: NIEPA.

3. Edwards, W. Deming (1982) : "Quality, Productivity, and Competitive Position”, MIT Press

4. Gupta, Asha (2005). International Trends in Higher Education and the Indian Scenario. CSHE Research and Occasional Paper Series Centre for Studies in Higher Education: University of California. Berkeley

5. Massy, William E. (2007) : Academic Quality Work, Anker Publishing

6. Ruben, Brent D. (2004) : "Pursuing Excellence in Higher Education”, JosseyBass

7. Thorat S.K. (2006) : "Higher Education in India - Emerging Issues Related to Access, Inclusiveness, and Quality"

8. Higher Education Commission (Radhakrishnan Commission) : (1948-49)

9. Kothari Commission : (1964-66)

10. National Education Policy : 1986

11. Revised National Education Policy : 1986 (1992)

12. National Knowledge Commission, Report to the Nation (2006), New Delhi (2007). 